\title{
Effects of canopy cover, herbivores and substratum type on patterns of Cystoseira spp. settlement and recruitment in littoral rockpools
}

\author{
Lisandro Benedetti-Cecchi, Francesco Cinelli
}

Dipartimento di Scienze dell'Ambiente e del Territorio Università di Pisa, Via A. Volta 6, I-56100 Pisa, Italy

\begin{abstract}
The effects of microhabitat types on patterns of Cystoseira spp. settlement and recruitment in littoral rockpools were examined in this study. Three experiments were carried out from July 1989 to December 1991 on the west coast of Italy (Western Mediterranean). By manipulation of (1) the adult canopy of Cystoseira spp., (2) herbivore density and (3) substratum type, we tested the general null hypothesis that the distribution and abundance of Cystoseira spp. embryos and juveniles were unaffected by microhabitat differences. Settlement was higher in patches of algal turfs than in areas covered by encrusting corallines or dominated by a full canopy of Cystoseira spp. In contrast, recruitment was significantly higher in plots dominated by encrusting and filamentous algae when herbivores were removed. Grazers (essentially limpets), if left at their natural density, greatly reduced the abundance of both Cystoseira spp. embryos and juveniles in these areas. Our results indicated that post-settlement mortality could reverse the patterns of recruit abundance expected from the distribution of settlers among microhabitats. The information gathered in this study will allow more accurate predictions of the spatial and temporal variability of Cystoseira populations in littoral rockpools.
\end{abstract}

\section{INTRODUCTION}

Although acknowledged for a long time, the ecological importance of factors affecting settlement and recruitment of marine benthic organisms has been more widely emphasized in recent years (Hawkins \& Hartnoll 1982, 1983, Underwood \& Denley 1984. Caffey 1985, Connell 1985, Roughgarden et al. 1985. Lewin 1986, Menge \& Sutherland 1987, Underwood \& Fairweather 1989). Variability in initial density of settlers and in post-settlement mortality may strongly affect the distribution and abundance of adult populations. Density-dependent processes, such as interspecific and intraspecific competition, may play an important role in mediating the relationships between settlement and recruitment (Connell 1985, Bertness 1989, Reed 1990, Reed et al. 1991). In addition, other density-independent factors, such as environmental stress, predation, canopy shading and sweeping effects, may also exert a strong negative impact on the survival of newly settled individuals (Connell 1961 ,
Hawkins 1983, Brawley \& Johnson 1991, Minchington \& Scheibling 1991).

Numerous studies on benthic macroalgae have evaluated various factors affecting species recruitment in space and time (e.g. Hawkins 1981, Lubchenco 1982, Jernakoff 1983, Dayton et al. 1984, Reed \& Foster 1984, Deysher \& Dean 1986, Kennelly 1987, Reed et al. 1988, Chapman 1989, 1990). By contrast, less information is available on the events occurring soon after propagule settlement (but see Reed 1990, Vadas et al. 1990, Brawley \& Johnson 1991). Brawley \& Johnson (1991) demonstrated that the survival of fucoid embryos depended upon the microhabitat into which they were outplanted. An adult canopy provided more protection against physical stress than patches of algal turfs and bare rock. Recruitment, however, was rare under the canopy while it normally occurred in algal turfs. These results suggest that although the early survival of newly settled propagules may be enhanced in a particular microhabitat, subsequent mortality may be greater there than at other sites. As a consequence, the 
patterns of abundance of fucoid embryos cannot be used to predict the distribution of juvenile and adult individuals. Hence, the study of the relationships between successive life history stages is of great importance to improve the predictive power of the models explaining the spatial and temporal distribution of benthic algal populations.

Algal mosaics dominating littoral pools on the west coast of Italy (Western Mediterranean) offered the opportunity to investigate the performance of Cystoseira spp. embryos and juveniles in a patchy habitat. Little experimental work has been done on ecological interactions involving Cystoseira spp. and the experimental approach has not been widely used in the Mediterranean (but see Benedetti-Cecchi \& Cinelli 1992). In this study, by manipulating the adult canopy, herbivore density and substratum type, we tested the general null hypothesis that the patterns of Cystoseira settlement and recruitment in iittoral pools were undfected by microhabitat differences.

\section{METHODS}

Study site and organisms. This study was carried out on the exposed rocky coast south of Livorno, Italy, $\left(43^{\circ}\right.$ $\left.30^{\prime} \mathrm{N}, 10^{\circ} 20^{\prime} \mathrm{E}\right)$ from July 1989 to December 1991. Eighteen pools were chosen for the experiments (a summary of the experimental designs used in this study is given in Table 1 ). They ranged in size from about 5 to $10 \mathrm{~m}^{2}$ and were located from 0.1 to $0.3 \mathrm{~m}$ above mean low level water. The algal assemblage was patchy, with stands of canopy-forming algae, consisting of Cystoseira brachycarpa J Agardh emend Giaccone var. balearica (Sauvageau) Giaccone, and C. compressa (Esper) Gerloff \& Nizzamuddin, interspersed among patches of encrusting and turf-forming algae. These were represented by articulated corallines, mainly Corallina elongata Ellis et Solander, and by fleshy red and brown algae such as Laurencia obtusa (Hudson) Lamouroux, Rytiphloea tinctoria (Clemente) C. Agardh, and Padina pavonica (Linnaeus) Thivy. Filamentous species, mainly consisting of Cla- dophora rupestris (Linnaeus) Kützing, Ceramium spp. and Polysiphonia spp., also occurred as epiphytes on the other plants. For the purpose of this study such algae were not included in the turf group, but were considered as a separate category.

The most common herbivores were the sea urchin Paracentrotus lividus (Lamark) and limpets (Patella spp.). The former were cryptic, spending most of their time in crevices, while the latter were abundant on patches of algal crusts. Further descriptions of the study site can be found elsewhere (Benedetti-Cecchi \& Cinelli 1992).

Expt 1: efiect of canopy removal. This experiment was designed to test the null hypothesis that embryo settlement was similar with and without Cystoseira spp. canopy. Embryos are defined here as microscopic germlings (ca $200 \mu \mathrm{m}$ long) invisible to the unaided eye. Four pools, all supporting a dense canopy of Cystoseira spp., were used as blocks in a randomized block design. Experimental units were $2 \mathrm{~m}^{2}$ plots randomly assigned to a control and to a canopy-removal treatment in each pool. Cystoseira spp. plants were removed from the substratum with a chisel in treatment plots, while they were left undisturbed in controls. This experiment started in July 1989 and lasted until July 1990.

The number of settled embryos was counted in $25 \mathrm{~cm}^{2}$ samples collected monthly in each plot and examined under a dissecting microscope. A permanent transect was established in each $2 \mathrm{~m}^{2}$ plot at the beginning of the experiment. Sampling dates were randomly assigned to $5 \times 5 \mathrm{~cm}$ squares along the transect, making sure that no 2 samples were closer than $0.5 \mathrm{~m}$.

Cystoseira brachycarpa var. balearica and C. compressa reproduced synchronously at our study site and both of them colonized the experimental plots. How ever, they were not distinguishable during the early stages of development and interspecific differences in settlement and recruitment patterns could not be assessed. Also, both treatment and control plots probably received more than 1 'pulse' of Cystoseira spp. embryos during the main settlement period (because of continuous gamete shedding), and a number of early

Table 1 Summary of the experiments used to study Cystoseira spp. settlement and recruitment in littoral rockpools

\begin{tabular}{|llll|}
\hline Study period & Treatment variables & Response variable & Experimental design \\
\hline Jul 1989-Jul 1990 & Canopy & Cystoseira spp. settlement & Randomized block design \\
May 1990-Aug 1990 & $\begin{array}{l}\text { Herbivores and } \\
\text { substratum type }\end{array}$ & Cystoseira spp. settlement & $\begin{array}{l}\text { Randomized block design } \\
\text { with a factorial structure }\end{array}$ \\
Apr 1991-Dec 1991 & $\begin{array}{l}\text { Canopy, herbivores } \\
\text { and substratum type }\end{array}$ & Cystoseira spp. recruitment & Randomized block design \\
\hline
\end{tabular}


post-settlement events, such as embryo displacement and/or 'trapping', could have occurred on a temporal scale of a few days. The sampling program adopted in this experiment did not allow us to detect such shortterm patterns. Therefore, we assumed that the density of embryos recorded each month in treatment and control plots reflected both the suitability of a given microhabitat for Cystoseira spp. settlement, and the performance of already settled embryos in that area. This explanation is important for the correct interpretation of the results, and the concept also applies to the following experiment.

Expt 2: effects of herbivores and substratum type. A factorial experiment was carried out from May to August 1990, to investigate the effects of herbivores and substratum type on embryo settlement. Four treatments were randomly assigned to large patches of algal crusts, interspersed among the canopy and the turfing algae in each of 4 replicate pools. Experimental units were $100 \mathrm{~cm}^{2}$ plots of the following treatments: (1) algal crusts, herbivores present (HC treatment); (2) algal crusts, herbivores excluded (NHC treatment); (3) transplanted algal turfs, herbivores present (HT treatment); (4) transplanted algal turfs, herbivores excluded (NHT treatment).

The algal turfs were collected with a paint scraper in pools devoid of Cystoseira spp. and about $2 \mathrm{~km}$ away from natural populations of fucoids, to ensure that no embryos were present in the turf matrix before the beginning of the experiment (for the same reason, the algal crusts in the $\mathrm{HC}$ and $\mathrm{NHC}$ treatments were also cleaned with a plastic brush before the start of the experiment). Samples of algae from the same pools were also examined in the laboratory and checked for Cystoseira spp. settlement. No embryos were ever recorded among these turfs throughout the study period.

The species composition of transplanted algae was the same as that in experimental pools. These species were joined in dense 'mats' 2 to $5 \mathrm{~cm}$ high, held together by the encrusting base of Corallina elongata. Samples of such 'mats' were glued to the substratum on $10 \times 10 \mathrm{~cm}$ plots, previously covered with a layer of marine epoxy putty about $0.5 \mathrm{~cm}$ thick.

Limpets were excluded from $20 \times 20 \mathrm{~cm}$ squares with stainless steel fences stuck to the substratum with the epoxy putty. The experimental plots were placed in the centre of these squares. Fences were $3 \mathrm{~cm}$ high and their upper edges were folded outwards to prevent small herbivores from climbing over. Sea urchins were absent in these pools throughout the study period.

Five $2 \mathrm{~cm}^{2}$ samples were randomly collected at the end of the experiment within each experimental unit by chiselling the algal crusts or the algal turfs (also the layer of epoxy putty was removed in this case)
Samples were then examined under a dissecting microscope, and the number of embryos was recorded.

Procedural controls for artifacts due to the fences were not included in this experiment. However, the data relative to another study indicated that fences similar to those described above (but $5 \mathrm{~cm}$ high) did not introduce artifacts. This experiment was carried out in 4 rockpools close to those used to study Cystoseira spp. settlement and was designed to investigate the effects of limpet exclusion on algal colonization. In this case the fences were fixed to the substratum with stainlesssteel screws inserted into rawl-plugs in the rock. These structures, however, were not effective to exclude limpets. Herbivores, in fact, were able to invade the exclusion areas by entering through the openings that remained between the rock and the fences (because of substratum roughness). Therefore, this experiment actually tested for effects of fences, not of grazers. As the total algal cover after 2 mo from the beginning of the study (started in December 1990 and abandoned 4 mo later) was very similar in treatment and control (unfenced) plots (mean \pm SE: $30 \% \pm 13.7$ and $31.5 \% \pm$ 13.9 respectively), we concluded that there were no artifacts attributable to fence structure. The same was assumed for the experiment reported in this paper.

Expt 3: patterns of recruitment. A randomized block design was used to test for the effects of canopy cover, herbivores and substratum type on Cystoseira spp. recruitment. Recruits are defined here as young plants (minimum size ca $1 \mathrm{~cm}$ ) visible to the unaided eye. Ten pools were used in this experiment. Each pool contained a replicate of 3 treatments, randomly assigned to $15 \times 15 \mathrm{~cm}$ plots with initial canopy cover. These treatments were: (1) controls (i.e. unmanipulated plots): (2) areas cleared of Cystoseira spp., exposing the understorey turfing algae; (3) areas cleared of Cystoseira spp and turfs, exposing the underlying encrusting algae. It was impossible for us to remove the turfs under the canopy without damaging Cystoseira spp. As a consequence, one treatment combination (algal turfs removed, canopy present) was not included in the experiment, which is presented here as an unbalanced design.

A surface of $100 \mathrm{~cm}^{2}$ was sampled every 2 months in the centre of each experimental unit using a nondestructive method. The corners of a $15 \times 15 \mathrm{~cm}$ plexiglass sheet, with 100 equally spaced dots, were placed over the small pieces of epoxy putty that were used to mark the corners of each plot. The percent cover of individual species was recorded as the number of dots lying over each organism. The abundance of understorey algae in control quadrats was assessed by moving aside the canopy of Cystoseira spp. Care was taken to maintain constant the accuracy of our sampling method across treatments. 


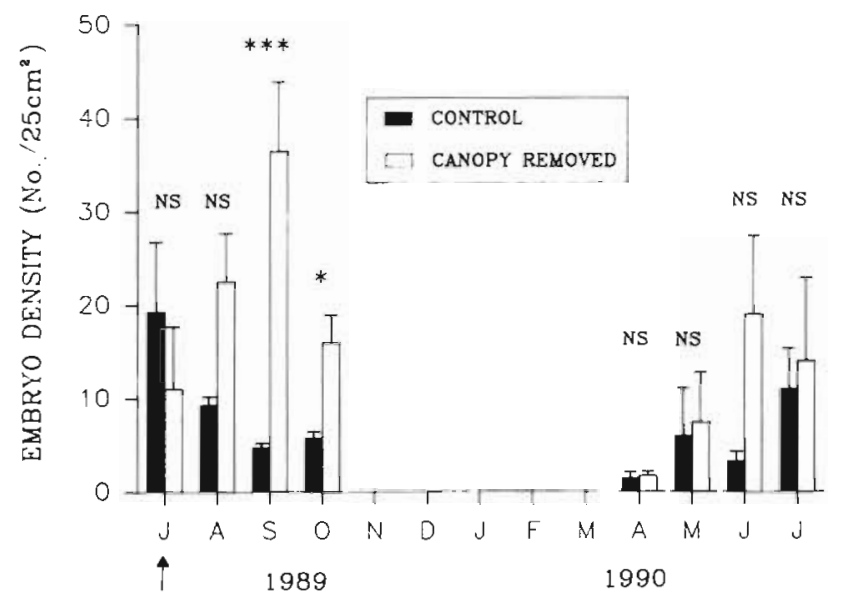

Fig. 1 Effect of Cystoseira spp. removal on embryo settlement. Values are means (+ SE) of untransformed data on 4 replicated pools. Treatments were compared by ANOVA for sandomized block designs on $\log (x+1)$ transformed data. Variances were homogeneous at each sampling date (Cochran's test). Probability plots of residuals were examined after an ANOVA was performed to determine if error terms were normally distributed. The Bonferroni correction was also used to maintain the total probability of type I error at the 0.05 level. NS: no significant difference; $" p<0.05$; $\cdots p<0.001 ;$ arrow: pre-treatment values

The effect of herbivores on Cystoseira spp. recruitment was assessed by hand removal of limpets and sea urchins from 5 out of 10 pools chosen at random. Visits every $2 \mathrm{wk}$ were sufficient to effectively reduce the abundance of grazers in these pools. The number of limpets was counted in $100 \mathrm{~cm}^{2}$ squares within each $15 \times 15 \mathrm{~cm}$ plot, while the density of sea urchins was assessed in two $1 \mathrm{~m}^{2}$ replicated quadrats randomly chosen in each experimental pool.

\section{RESULTS}

\section{Expt 1}

Cystoseira spp. embryos were detected in both control and treatment plots from July to October 1989 and from April to July 1990 (Fig 1). The removal of Cystoseira spp. significantly increased the density of settlers after 2 and 3 mo from the start of the experiment (ANOVAs for randomized block designs). Embryo density remained higher in treatments than in controls during the second settlement period, although no significant differences were found at that time.

\section{Expt 2}

Tufts of filamentous green algae (Cladophora spp.) developed in the NHC quadrats, and to a lesser extent in the other treatments, soon after the start of the experiment. To maintain the variable 'substratum' constant across levels of the factor 'herbivores', we decided to stratify the $2 \mathrm{~cm}^{2}$ samples within patches of encrusting corallines in the $\mathrm{HC}$ and $\mathrm{NHC}$ quadrats, and within the turfs not covered by filamentous algae in the HT and NHT plots.

Treatments significantly influenced Cystoseira spp. settlement in the experimental pools $(p<0.05$; ANOVA for randomized block designs on log-transformed data. The five $2 \times 2 \mathrm{~cm}$ samples collected from each experimental unit were pooled for the analysis). Unplanned comparisons (Ryan-Elinot-Gabriel-Welsh multiple-range test; SAS Institute Inc. 1985) indicated that embryos were more abundant among the algal turfs than on the encrusting corallines, while the exclusion of herbivores had no detectable effects on Cystoseira spp. settlement (Fig. 2). Limpets, however, apparently grazed only on the algal crusts during the daytime (we have no data on the nocturnal activity of these herbivores), as they were found in the $\mathrm{HC}$ quadrats at the density of $2.75 \pm 0.95$ ind. $100 \mathrm{~cm}^{-2}$ ( 4 replicates, at end of experiment), but not in the other treatments. They were also present at the edge of the HT plots, grazing on the smooth surface of the epoxy putty, but they were never seen over or between the algal turfs. From these observations, one would expect a sig-

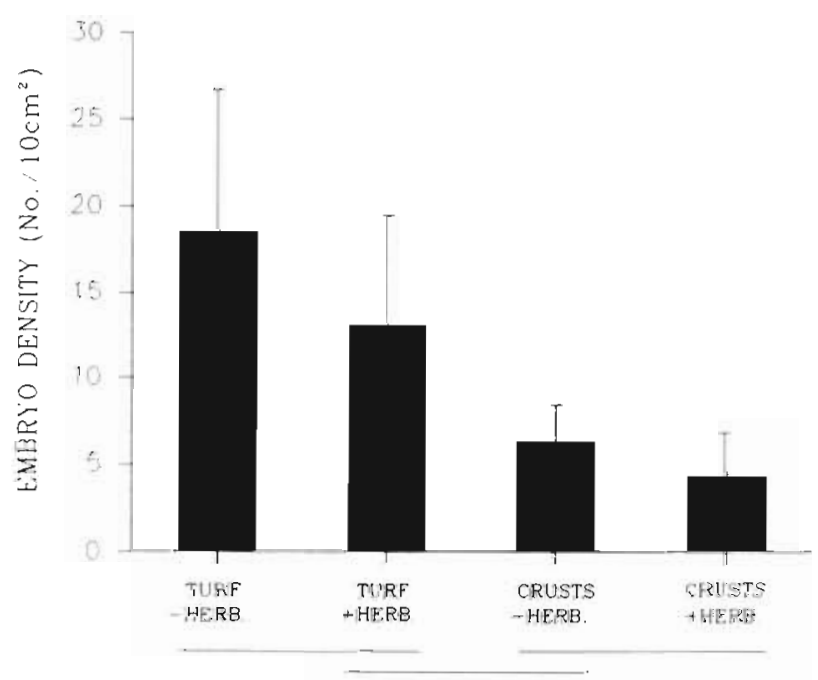

Fig. 2, Effects of herbivores and substratum type on Cystoseira spp. settlement. Values are mean (+ SE) numbers of embryos pooled from 5 replicated samples in each of 4 replicated treatments. Untransformed data are plotted. The data were analysed with ANOVA for randomized block design with pools as blocks and the other treatments considered as a single factor (variances were homogeneous, Cochran's test). Probability plots of residuals indicated that the data were normally distributed. Treatments that did not significantly differ (at $\mathrm{p}<0.05$ ) are connected by lines (Ryan-Elinot-GabrielWelsch multiple-range test; SAS Institute Inc. 1985) 
nificant interaction between substratum type and herbivores, as the algal turfs would provide a spatial refuge from predation for Cystoseira spp. embryos. This was not the case (Fig 2), and the null hypothesis that Cystoseira spp. settlement was not affected by limpets was retained (but see 'Discussion').

\section{ENCRUSTING ALGAE}

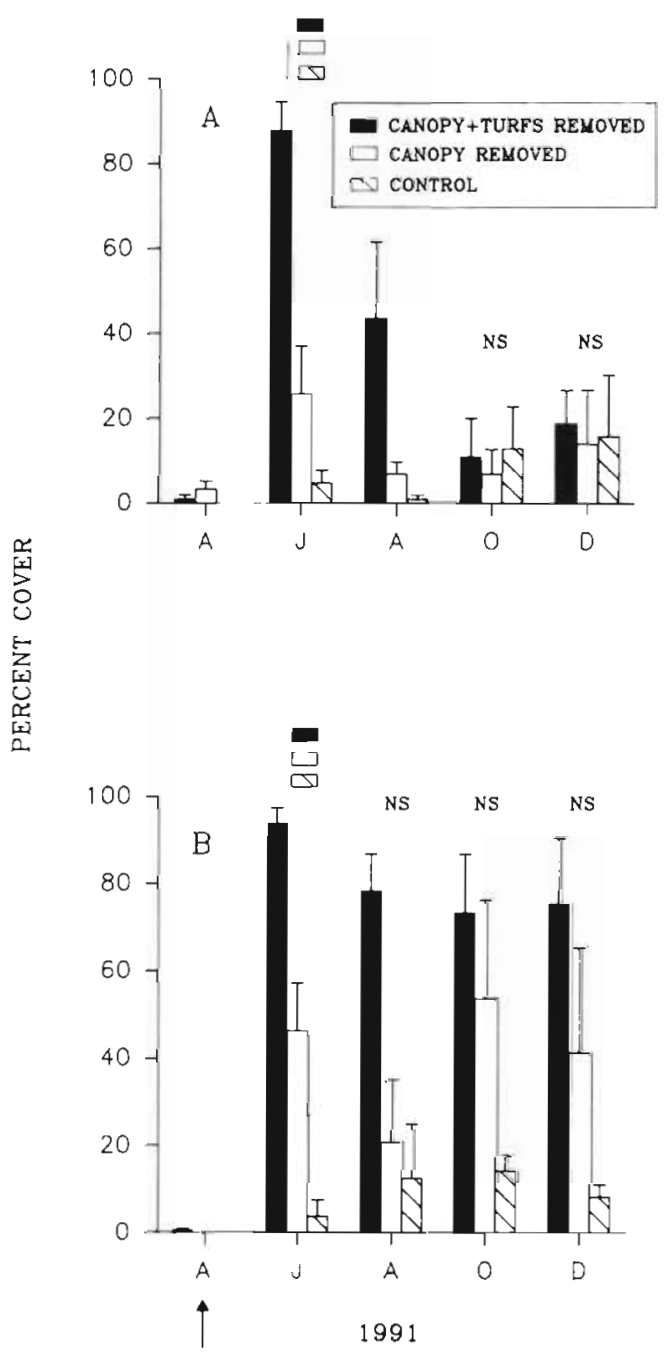

Fig. 3. Effects on encrusting algae due to the manipulation of Cystoseira spp., herbivores and turfs in treatment areas with (A) herbivores removed and (B) herbivores present. Values are mean percent covers ( + SE) of untransformed data on 5 replicates. At each sampling date, treatments with homogeneous variances (Cochran's test) were compared by ANOVA. for randomized block designs on arcsine transformed data (with the Bonferroni correction). Probability plots of residuals were examined after an ANOVA was performed to determine if error terms were normally distributed. Symbols connected by a line indicate a non-significant difference (at $p<0.05$ ) between the corresponding treatments (Ryan-Elinot-GabrielWelsch multiple-range test; SAS Institute Inc. 1985). NS: no significant difference; arrow: pre-treatment values

\section{Expt 3}

The substratum available for Cystoseira spp. settlement and subsequent recruitment differed greatly among treatments. Encrusting and filamentous algae were dominant in plots where both the canopy and the algal turfs were removed and in pools with reduced densities of herbivores (Figs. 3A \& 4 A). Percent cover of encrusting corallines declined after August 1991, as the abundance of filamentous green algae increased. Significant $(p<0.001)$ differences, however, were detected only for the former group (Fig. 3A) in June 1991 (ANOVA for randomized block designs). In contrast, the plots cleared of Cystoseira spp. only were dominated by algal turfs throughout the study period (Fig. 5A). Significant differences among treatments were found in August and October 1991 at $p<0.01$ and $p<$ 0.05 respectively (ANOVAs for randomized block designs). Small patches of encrusting corallines were also present within these plots, while filamentous algae mainly accurred as epiphytes on the algal turfs.

FILAMENTOUS ALGAE

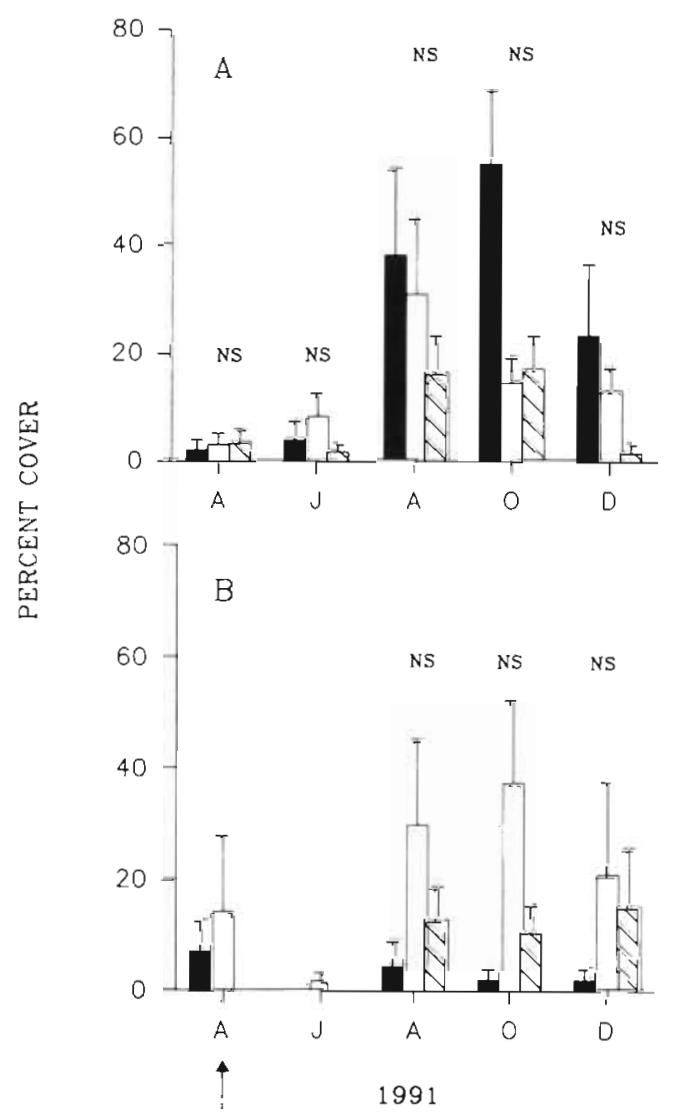

Fig. 4. Effects on filamentous algae due to the manipulation of Cystoseira spp., herbivores and turfs in treatment areas with (A) herbivores removed and (B) herbivores present. Analysis and symbols as in Fig. 3 


\section{TURFING ALGAE}

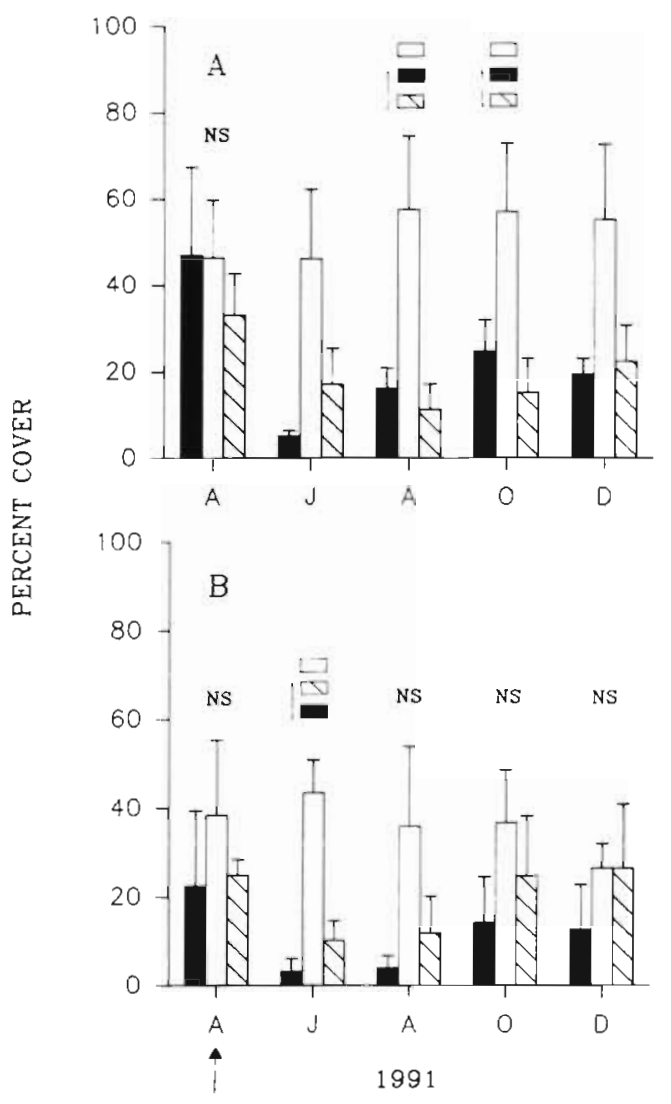

Fig. 5. Effects on turfing algae due to the manipulation of Cystoseira spp., herbivores and turfs in treatment areas with (A) herbivores removed and (B) herbivores present. Analysis and symbols as in Fig. 3

Percent cover of encrusting, filamentous and turfing algae remained low in control plots, which were dominated by a full canopy of Cystoseira spp.

Encrusting corallines dominated the substratum in areas cleared of Cystoseira spp. and algal turfs and exposed to natural densities of herbivores, until the end of the experiment (Fig. 3B). A significant difference $(p<0.001)$ among treatments was found in June 1991 (ANOVA for randomized block designs). Percent cover of encrusting algae was also high in plots cleared of Cystoseira spp. only, especially in comparison with the same treatments in pools where the density of herbivores was reduced (Fig. 3A, B). Grazers strongly affected the abundance of filamentous algae in areas completely cleared of erect plants. Their cover was greater in quadrats where only Cystoseira spp. was removed, although no significant differences among treatments were detected (Fig. 4B). Turfing algae were also more abundant in these areas than in the other plots (Fig. 5B). A significant $(p<0.05)$ effect was found in June 1991 (ANOVA for randomized block designs). No differences in algal cover were evident among control plots exposed to herbivores and those unaffected by grazers.

Substratum type greatly influenced Cystoseira spp. recruitment in areas where grazing pressure was reduced (Fig. 6A). Recruits were more abundant in quadrats cleared of both the canopy and the algal turfs than in the other treatments. A significant $(p<0.05)$ effect was found in December 1991 (ANOVA for randomized block designs). Thus, a substratum covered by encrusting and filamentous algae represented a more suitable site for Cystoseira spp. recruitment than areas dominated by algal turfs or by a full canopy of Cystoseira spp.

No significant differences in recruit density were found among treatments exposed to herbivores (Fig. 6B). Grazers drastically reduced the abundance of Cysluseira spp. juveniles in areas cleared of erect macroalgae and in quadrats where only the canopy had been removed. Recruitment remained low in control plots exposed to herbivores as well as in those where the grazing pressure was reduced (Fig. 6A, B).

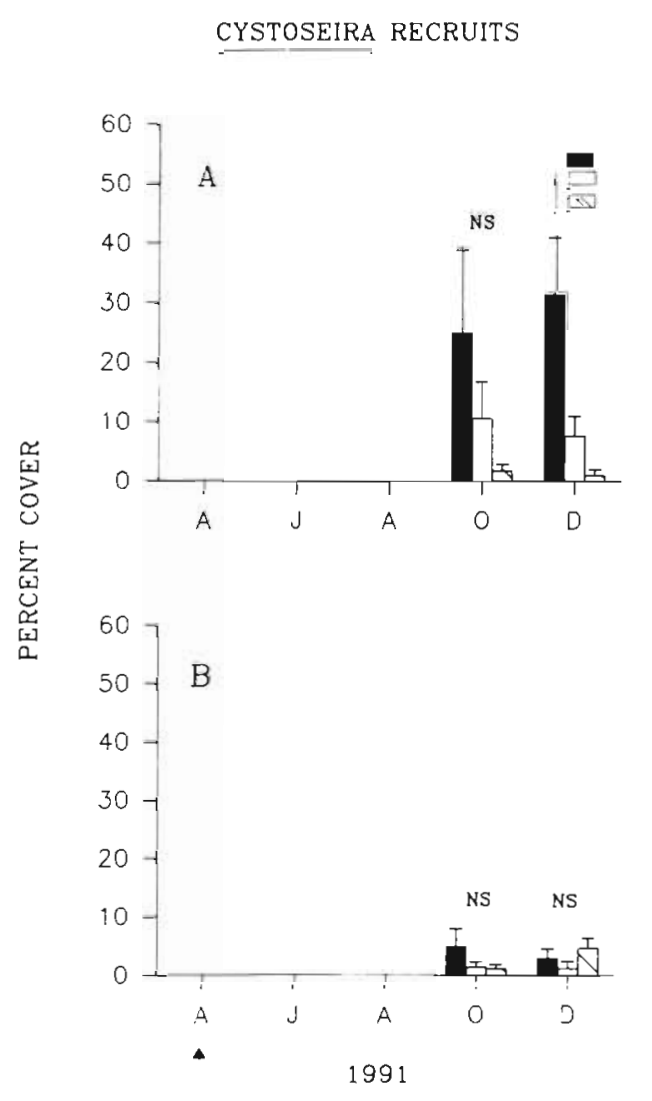

Fig. 6. Effects on Cystoseira spp. recruits due to the manipulation of the adult canopy, herbivore density, and algal turfs in treatment areas with (A) herbivores removed and (B) herbivores present. Analysis and symbols as in Fig. 3 


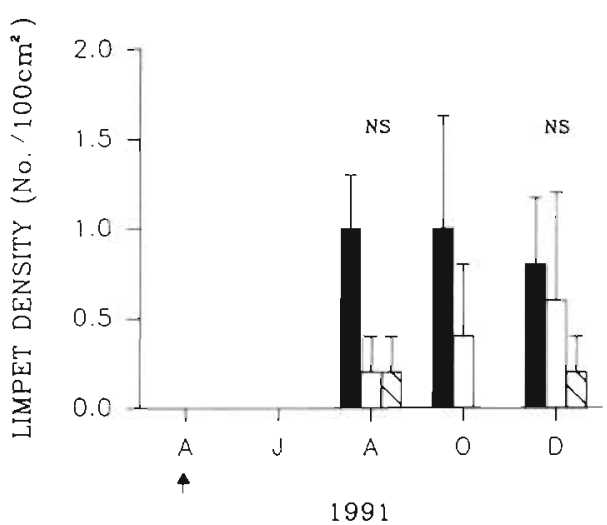

Fig. 7. Effects on limpets due to the manipulation of Cystoseira and algal turfs in pools with natural densities of herbivores. Analysis as in Fig. 3 except that data were $\log (x+1)$ transformed for ANOVA. Symbols as in Fig. 3

Generally, limpets were more abundant in areas completely cleared of erect macroalgae (Fig. 7). However, they were also present in small patches of encrusting corallines within the other plots, and no significant differences were found among treatments.

Sea urchin abundance ranged from $6.3 \pm 1.5$ to $23 \pm$ 9.4 ind $\mathrm{m}^{-2}$, in pools with natural densities of herbivores (Table 2). They were cryptic and their foraging activity was limited to barren areas just in front of their crevices, which remained separated from the experimental quadrats by patches of erect macroalgae. Circumstantial observations indicated that these patterns of distribution also occurred at night, although quantitative data were not collected. Therefore, these grazers probably exerted only a slight impact on the algal cover of treatment plots.

\section{DISCUSSION}

The results of these experiments indicated that microhabitat differences strongly affected Cystoseira spp. settlement and recruitment in littoral rockpools. The algal turfs enhanced embryo settlement in comparison with patches of encrusting corallines, whereas

Table 2. Paracentrotus lividus. Sea urchin density in experimental pools. Values are mean ( $\pm \mathrm{SE}$ ) numbers of individuals in $1 \mathrm{~m}^{2}$ plots $(\mathrm{n}=10)$

\begin{tabular}{|lrrrr|}
\hline Treatment & Apr & Jul & Aug & Nov \\
\hline Herbivores present & 6.3 & 12.0 & 11.3 & 23.0 \\
& $( \pm 1.5)$ & $( \pm 5.4)$ & $( \pm 2.5)$ & $( \pm 9.4)$ \\
Herbivores removed & 5.8 & 3.3 & 1.2 & 3.8 \\
& $( \pm 1.3)$ & $( \pm 1.1)$ & $( \pm 0.6)$ & $( \pm 1.0)$ \\
\hline
\end{tabular}

the opposite trend was evident when recruitment was considered. Thus, post-settlement mortality reversed the expected patterns of abundance of recruits, based on the distribution of settled embryos among these microhabitats. In contrast, both settlement and recruitment were inhibited under a full canopy of Cystoseira spp. The most probable causes of post-settlement mortality associated with the turfs and the canopy were competition for light and perhaps nutrients (Reed \& Foster 1984, Schiel \& Foster 1986, Kennelly 1987). Other factors, such as the abrasive action of algae (Dayton 1975, Velimirov \& Griffiths 1979) and allelopathic effects (Fletcher 1975), may have contributed to a reduction in the number of settled embryos.

Several factors could explain the enhancement of initial settlement by the turfs, in comparison with areas covered by encrusting corallines. Vadas et al. (1990) found that wave action was a major source of mortality for recently settled zygotes of Ascophyllum nodosum (Linnaeus) Le Jolis, another fucoid alga. Patches of algal turfs might provide a refuge from water displacement, representing a suitable site for zygote settlement (Brawley \& Johnson 1991). In addition, the turf microhabitat could also offer a refuge from herbivores. Grazers such as limpets generally feed on diatoms and algal sporelings over a substratum of encrusting corallines or bare rock (Branch 1981). Turf-forming algae, in contrast, may limit the feeding activity and the distribution of these organisms (Underwood \& Jernakoff 1981, Jernakoff 1985). Our results also support this view. Patella spp., in fact, were never seen grazing over or between the transplanted turfs in both fenced and unfenced plots. A similar trend also emerged from the experiment designed to study Cystoseira spp. recruitment. In general, limpets were more abundant in areas completely cleared of erect macroalgae than in plots covered by algal turfs or dominated by an adult canopy of fucoids. Moreover, even in these treatments, grazers were always seen within patches of algal crusts. The effect of herbivores on Cystoseira spp. settlement, however, appeared unimportant in our experiment (Fig. 2), in contrast with the above observations. Possibly, this result was a consequence of the low power of the statistical test used to compare treatment means. Unplanned comparisons which control the experimentwise error rate (like the Ryan-Elinot-GabrielWelsh test) are conservative when the sample size is small (Day \& Quinn 1989). It is likely that the incapability of our analysis to detect a significant effect of herbivores came from the limited number of replicates in the experiment $(n=4)$. In addition, mesograzers associated with the tufts of Cladophora spp. and also blennid fishes, which were present in the experimental pools, could have affected the number of embryos in both the fenced and unfenced treatments in such a way as to 
obscure the effect of Patella spp. in the HC and HT plots. The lack of a significant difference among the HT and NHC treatments, however, suggests the possibility of a balance between grazing and substratum type effects. Although limpets were never seen over or between the transplanted turfs, as stated above, our observations were done only during the daytime, while Patella spp. could have invaded the HT plots at night. Some herbivores, particularly mesograzers, are known to increase their mobility at night (Brawley 1992). Unfortunatly, the nocturnal activity of Patella spp. was not monitored during this study and the question remains unresolved. It is evident that further investigations involving more replication, the manipulation of grazers other than limpets and additional data on the distribution of herbivores at night, are necessary to elucidate these apparently complex interactions.

In contrast with the above results, Patella spp. gredily reduced Cysloseira spp. recruitment in the experimental pools (Fig. 6B). The importance of herbivores in regulating the abundance of fucoid algae has also been demonstrated by other authors. Lubchenco (1982) found that the removal of grazing gastropods (and algal competitors) from tidepools resulted in the colonization of Fucus vesiculosus (Linnaeus) in New England, USA. A similar result was found by Chapman (1990) in Nova Scotia, Canada, where the exclusion of littorinids and amphipods resulted in the establishment of $F$. distichus Linnaeus in littoral fringe tidepools. In contrast, little is known about the feeding ecology of sea urchins in these habitats (but see Paine \& Vadas 1969). In our pools these herbivores were cryptic, feeding on drifting algae or in patches of encrusting corallines near their crevices. Their removal, however, allowed Cystoseira to recruit in these areas (Benedetti-Cecchi \& Cinelli unpubl. data). Thus, sea urchins too had some influence on the distribution of fucoid algae in littoral pools.

Algal turfs are known to inhibit the recruitment of large macroalgal species in some subtidal areas (Brawley \& Adey 1981, Chapman 1984, Dayton et al. 1984, Kennelly 1987). Kennelly (1987), working in New South Wales, Australia, indicated that these species were persistent enough to be considered as an alternative 'stable state' of the kelp community, over a scale of time of 1 to 2 yr In our pools, the turfs were resistant to the invasion of Cystoseira spp., and they probably were only little affected by herbivores (with the exception of the plants subjected to the grazing activity of sea urchins). Moreover, these species were able to replace the fucoids once the canopy had been removed (Benedetti-Cecchi \& Cinelli 1992). Thus, the persistence of these algae was greater than would be expected if they were subjected to competitive exclusion and intense predation.
Disturbance can be of great importance in promoting spatial and temporal heterogeneity in natural communities (Paine \& Levin 1981, Dethier 1984, Sousa 1984). Both physical and biological factors may contribute to the formation of clearings in algal assemblages, exposing the underlying encrusting organisms (Lawrence 1975, Ayling 1981, Steneck 1986). Patches of encrusting corallines were an important element of the algal mosaic in littoral pools. Circumstantial observations indicated that such areas were produced mainly by storms, whereas herbivores enabled their persistence by inhibiting algal recovery. The experimental evidence presented here also supports this view, in that limpets were able to invade artificially cleared plots where they reduced algal recruitment.

In summary, microhabitat types differentially affected initial density and post-settlement mortality of Cystoseira spp. embryos. Such processes greatly influenced the distribution of recruits within the algal mosaics. The information gathered in this study indicated that the persistence of Cystoseira spp. populations depended upon the availability of patches of encrusting corallines with a reduced density of herbivores. These results may improve our understanding of community organization in littoral rockpools of the Mediterranean, allowing more accurate predictions on the distribution and abundance of the dominant species

Acknowledgements. We sincerely thank S. J. Hawkins for valuable comments on the manuscript. This work was supported by a MURST $60 \%$ project to F.C.

\section{LITERATURE CITED}

Ayling, A. M. (1981). The role of biological disturbance in temperate subtidal encrusting communities. Ecology 62: $830-847$

Benedetti-Cecchi, L., Cinelli, F. (1992). Canopy removal experiments in Cystoseira dominated rockpools from the Western coast of the Mediterranean (Ligurian Sea). J. exp. mar. Biol. Ecol. 155: 69-83

Bertness, M. D. (1989). Intraspecific competition and facilitation in a northern acom barnacle population. Ecology 70 : $257-268$

Branch, G. M. (1981). The biology of limpets: physical factors, energy flow, and ecological interactions. Oceanogr. mar Biol. A. Rev. 19: 235-380

Brawley, S. H (1992). Mesoherbivores. In: John, D. M. Hawkins, S. J., Price, J. H. (eds.) Plant-animal interactions in the marine benthos. Oxford Univ. Press, Oxford, p. 235-263

Brawley, S. H, Adey, W. H. (1981). The effect of micrograzers on algal community structure in a coral reef microcosm. Mar. Biol. 61. 167-177

Brawley, S. H., Johnson, L. E. (1991). Survival of fucoid embryos in the untertidal zone depends upon developmental stage and microhabitat. J. Phycol. 27: 179-186

Caffey, H. M. (1985). Spatial and temporal variation in settlement and recruitment of intertidal barnacles. Ecol. Monogr. 55: 313-332 
Chapman, A. R. O. (1984). Reproduction, recruitment and mortality in two species of Laminaria in southwest Nova Scotia. J. exp. mar Biol. Ecol. 78: 99-109

Chapman, A. R. O. (1989). Abundance of Fucus spiralis and ephemeral seaweeds in a high eulittoral zone: effects of grazers, canopy and substratum type. Mar. Biol. 102: $565-572$

Chapman, A. R. O. (1990). Eftects of grazing, canopy cover and substratum type on the abundance of common species of seaweeds inhabiting littoral fringe tide pools. Botanica mar. 33: 319-326

Connell, J. H. (1961). Effects of competition, predation by Thais lapillus, and other factors on natural populations of the barnacle Balanus balanoldes. Ecol. Monogr. 31: $61-104$

Connell, J. H. (1985). The consequences of variation in initial settlement vs. post-settlement mortality in rocky intertidal communities. J. exp. mar. Biol. Ecol. 93: 11-45

Day, R. W., Quinn, G. P. (1989). Comparisons of treatments after an analysis of variance in ecology. Ecol. Monogr. 59 . $433-463$

Dayton, P. K. (1975). Experimental evaluation of ecological dominance in a rocky intertidal algal community. Ecol. Monogr. 45: 137-159

Dayton, P. K., Currie, V., Gerrodette, T., Keller B. D., Rosenthal, R., Tresca, D. V. (1984). Patch dynamics and stability of some California kelp communities. Ecol. Monogr 54: $253-289$

Dethier, M. N. (1984). Disturbance and recovery in intertidal pools: maintenance of mosaic patterns. Ecol. Monogr. 54: 99-118

Deysher, L., Dean, T. A. (1986). In situ recruitment of the giant kelp, Macrocystis pyrifera: effects of physical factors. J. exp. mas. Biol. Ecol. 103: 41-63

Fletcher, R. L. (1975). Heteroantagonism observed in mixed algal cultures. Nature 253: $534-535$

Hawkins, S. J. (1981). The influence of season and barnacles on the algal colonization of Patella vulgata exclusion areas. J. mar. biol. Ass. U.K. 61. 1-15

Hawkins, S. J. (1983). Interactions of Patella and macroalgae with settling Semibalanus balanoides (L.). J. exp. mar. Biol. Ecol. 71: 55-72

Hawkins, S. J., Hartnoll, R. G. (1982). Settlement patterns of Semibalanus balanoides (L.) on the Isle of Man (1977-1981). J. exp. mar. Biol. Ecol. 62: 271-283

Hawkins, S. J., Hartnoll, R. G. (1983). Grazing of intertidal algae by marine invertebrates. Oceanogr mar Biol. A. Rev. 21: 195-282

Jernakoff, P. (1983). Factors affecting the recruitment of algae in a midshore region dominated by barnacles. J. exp. mar. Biol. Ecol. 67: 17-31

Jernakoff, P. (1985). Interactions between the limpet Patellorda latistrigata and algae on an intertidal rock platform. Mar. Ecol. Prog. Ser. 23: 71-78

Kennelly, S. J. (1987). Inhibition of kelp recruitment by turfing algae and consequences for an Australian kelp community. J. exp. mar. Biol. Ecol. 112: 49-60

Lawrence, J. M. (1975). On the relationships between marine plants and sea urchins. Oceanogr. mar. Biol. A. Rev. 13: 213-286
Lewin, R. (1986). Supply-side ecology. Science 234: 25-27

Lubchenco, J. (1982). Effects of grazers and algal competitors on fucoid colonization in tide pools. J. Phycol. 18: 544-550

Menge, B. A., Sutherland, J. P. (1987). Community regulation varlation in disturbance, competition, and predation in relation to environmental stress and recruitment. Am. Nat 130: $730-757$

Minchington, T E., Scherbling, R. E. (1991). The influence of larval supply and settlement on the population structure of barnacles. Ecology 72: 1867-1879

Paine, R.T., Levin, S. A. (1981). Intertidal landscapes: disturbance and the dynamics of pattern. Ecol. Monogr 51 $145-178$

Paine, R. T., Vadas, R. L. (1969). The effects of grazıng by sea urchins, Strongylocentrotus spp. on benthic algal populations. Limnol. Oceanogr. 14: 710-718

Reed, D. C. (1990). The effects of variable settlement and early competition on patterns of kelp recruitment. Ecology $71.776-787$

Reed, D. C., Foster, M. S. (1984). The effects of canopy shading on algal recruitment and growth in a giant kelp forest. Ecology 65: 937-948

Reed, D. C., Laur, D. R., Ebeling, A. W. (1988). Variation in algal dispersal and recruitment: the importance of episodic events. Ecol. Monogr. 58: 321-335

Reed, D. C., Neushul, M., Ebeling, A. W. (1991). Role of settlement density on gametophyte growth and reproduction in the kelps Pterygophora californica and Macrocystis pyrifera (Phaeophyceae). J. Phycol. 27: 361-366

Roughgarden, J., Iwasa, Y., Baxter, C. (1985). Demographic theory for an open marine population with space-limited recruitment. Ecology 66: 54-67

SAS Institute Inc. (1985). SAS users' guide: statistics. SAS Institute Lnc. Cary, NC

Schiel, D. R., Foster, M. S. (1986). The structure of subtidal algal stands in temperate waters. Oceanogr mar. Biol. A. Rev. 24: 265-307

Sousa, W. P. (1984). The role of disturbance in natural communities. A. Rev. Ecol. Syst. 15: 353-391

Steneck, R. S. (1986). The ecology of coralline algal crusts convergent patterns and adaptive strategies. A. Rev. Ecol. Syst. 17: 273-303

Underwood, A. J., Denley, J. (1984). Paradigms, explanations and generalizations in models for the structure of intertidal communities on rocky shores. In: Strong, D. R., Simberloff, D., Abele, L. G., Thistle, A. B. (eds.) Ecological communities: conceptual issues and the evidence. Princeton University Press, Princeton, p. 151-180

Underwood, A. J., Fairweather, P. G. (1989). Supply-side ecology and benthic marine assemblages. Trends Ecol. Evol. (TREE) 4: 16-20

Underwood, A. J., Jernakoff, P. (1981). Interactions between algae and grazing gastropods in the structure of a low shore algal community. Oecologia 48: 221-233

Vadas, R. L., Wright, W. A., Miller, S. L. (1990). Recruitment of Ascophyllum nodosum: wave action as a source of mortality. Mar. Ecol. Prog. Ser. 61: 263-272

Velimirov, B., Griffiths, C. L. (1979). Wave-induced kelp movement and its importance for community structure. Botanica Mar. 22: 169-172

Manuscript first received: April 4, 1992

Revised version accepted: October 22, 1992 